\title{
Sintomas de deficiência de macronutrientes em alface
}

\author{
Macronutrient deficiency symptoms in lettuce
}

\begin{abstract}
Arthur Bernardes CECíLIO FILHO무 Marilsa Aparecida RODRIGUES ${ }^{1}$; Maria Letícia Pacheco da SILVA ${ }^{1}$; Juan Waldir Mendoza CORTEZ ${ }^{2}$

1 Universidade Estadual Paulista, Faculdade de Ciências Agrárias e Veterinárias, Depto. de Ciências da Produção Agrícola, Via de acesso Prof. Paulo D. Castellane, 14884-900, Jaboticabal, SP, Brasil; aprog@ig.com.br; arthur.cecilio@unesp.br; mlpacheco_90@hotmail.com

${ }^{2}$ Universidad Nacional Agraria La Molina, Av. La Molina, s/n, 15024, La Molina, Lima, Peru; jmendoza@lamolina.edu.pe
\end{abstract}

Recebido em: 18-04-2020; Aceito em: 15-06-2020

\section{Resumo}

O diagnóstico de problemas nutricionais mediante a observação de sintomas tem grande importância prática porque permite tomar decisões rápidas no campo para a correção das deficiências. O objetivo do trabalho foi descrever e fotografar os efeitos das omissões de cada macronutriente em alface. O experimento foi conduzido em hidroponia, na UNESP, Câmpus de Jaboticabal, SP. Os tratamentos foram aplicados às cultivares Oak Leaf Red Pixie (grupo crespa, sem cabeça, folhas avermelhadas), Lucy Brown (grupo americana, lisa, folhas verdes) e Verônica (grupo crespa, sem cabeça, folhas verdes). Os tratamentos com omissão de $\mathrm{P}$ e Ca na solução nutritiva foram aplicados no mesmo dia do transplante das mudas de alface do berçário para os canais de crescimento final. Quatro dias após foram aplicadas as soluções com omissão de $\mathrm{N}, \mathrm{K}$ e Mg. Os sintomas de deficiências surgiram na seguinte ordem: $\mathrm{N}, \mathrm{K}, \mathrm{Mg}, \mathrm{P}$ e Ca. Os sintomas de carência nutricional foram facilmente visualizados em 'Verônica' e 'Lucy Brown' e dificilmente na 'Oak Leaf Red Pixie' devido à coloração avermelhada da folha. A omissão de nutrientes compromete o aspecto comercial da alface e as omissões de $\mathrm{N}, \mathrm{K}, \mathrm{Ca}$ e $\mathrm{Mg}$ esse comprometimento ocorre já na fase inicial dos sintomas.

Palavras-chave adicionais: deficiência nutricional; Lactuca sativa, nutrição mineral.

\begin{abstract}
Diagnosis of nutritional problems through observation of symptoms has great practical importance because it allows making quick decisions in the field for correction of deficiencies. This study aimed to describe and photograph the effects of macronutrient omission in lettuce cultivars. The experiment was conducted in hydroponic, at UNESP, Campus of Jaboticabal in São Paulo State. Treatments were applied to cultivars Oak Leaf Red Pixie (crisp group without head, reddish leaves), Lucy Brown (American group, smooth, green leaves) and Veronica (crisp group without head, green leaves). Treatments with the omission of $\mathrm{Ca}$ and $\mathrm{P}$ in nutrient solution were applied on the same day that the lettuce seedlings were transplanted from nursery to the channels of final growth. After four days, it was applied the solutions with the omission of $\mathrm{N}, \mathrm{K}$ and $\mathrm{Mg}$. Symptoms of deficiency occur in the following order: $\mathrm{N}, \mathrm{K}, \mathrm{Mg}, \mathrm{P}$ and $\mathrm{Ca}$. The nutritional deficiency symptoms were easily observed in 'Veronica' and 'Lucy Brown' and hardly identified in the 'Red Oak Leaf Pixie' due to reddish color of leaves. The omission of nutrients compromises the commercial aspect of the lettuce and the omissions of $\mathrm{N}, \mathrm{K}, \mathrm{Ca}$ and $\mathrm{Mg}$ this compromise occurs already in the initial phase of the symptoms.
\end{abstract}

Additional keywords: Lactuca sativa, mineral nutrition, nutritional deficiency.

\section{Introdução}

A alface é a principal hortaliça-folhosa cultivada e consumida no Brasil, estando entre as dez hortaliças mais apreciadas para consumo in natura (Sala \& Costa, 2012). Representa $90 \%$ dos cultivos hidropônicos sendo o sistema NFT (Nutriente
Film Technique) o mais utilizado para a sua produção (Ohse et al., 2001).

Como se trata de uma hortaliça cultivada em todo o território brasileiro, há grande variação no ambiente de cultivo, sobretudo quanto ao clima e solo, com respostas distintas para uma mesma cultivar e manejo. 
Para que produtores e técnicos tenham condições de aprimorar o manejo cultural, há necessidade de fazer o acompanhamento do estado nutricional, que permite avaliar a resposta da planta não só à adubação, mas também à interação desta com todo o sistema de produção. Conhecer o estado nutricional da planta permite identificar quais nutrientes estão limitando o crescimento, o desenvolvimento, a produção e a qualidade da hortaliça. Contudo, na literatura, quando existentes, há fotografias de sintomas severos de deficiência nutricional, o que pouco interessa ao produtor e técnico extensionista (Silva, 2006). Nesse sentido, há necessidade de ter fotos de carências desde o início de visualização do sintoma e a sua evolução. De acordo com Nafiu et al. (2012) e Vidigal et al. (2019), o diagnóstico de problemas nutricionais, mediante a observação de sintomas, tem grande importância prática porque permite tomar decisões rápidas no campo para a correção das deficiências.

Assim, objetivou-se descrever e fotografar os efeitos da omissão de cada macronutriente em cultivares de alface.

\section{Material e métodos}

O experimento foi conduzido em hidroponia, técnica "nutrient film technique" (NFT), em casa de vegetação do Setor de Olericultura e Plantas Aromático-Medicinais, pertencente à UNESP, Câmpus de Jaboticabal, no estado de São Paulo, situado à 21015'22" Sul e 48'18'58'" Oeste, e altitude de 575 metros.

As mudas de alface das cultivares Oak Leaf Red Pixie (grupo crespa, sem cabeça, folhas avermelhadas), Lucy Brown (grupo americana, lisa, verde) e Verônica (grupo crespa, sem cabeça, verde) foram formadas em placas de espuma fenólica, com unidades (células) de $2 \times 2 \times 2 \mathrm{~cm}$, com uma planta de alface por célula. Previamente à semeadura, realizou-se a lavagem da espuma em água corrente, por 5 minutos, para eliminação de resíduos. A placa de espuma fenólica semeada foi acondicionada em casa de vegetação, para germinação, emergência e crescimento inicial, recebendo apenas água corrente (Fase 1).

Após 10 dias da emergência, as células da espuma fenólica foram separadas e as mudas foram transferidas para canais de polipropileno de cultivo hidropônico, de $5 \mathrm{~cm}$ de largura, no sistema NFT com reaproveitamento e recirculação da solução nutritiva. O fornecimento da solução nutritiva foi intermitente, alternando-se 15 minutos com circulação e 15 minutos sem circulação. Os canais desta estrutura, denominada de berçário, tinham $5 \%$ de declividade e corresponderam à fase 2 do crescimento das plantas, onde permaneceram por 22 dias antes de seguirem para os canais de crescimento final (Fase 3).

$\mathrm{Na}$ época do transplante para os canais de crescimento fase 3, 15 plantas de cada cultivar foram aleatoriamente amostradas, e tiveram seu crescimento quantificado. As plantas de alface 'Oak Leaf Red Pixie', 'Lucy Brown' e 'Verônica' apresentavam 7,2; 6,6 e 5 folhas; 160, 175 e 170 cm$^{2}$ de área foliar e 0,4;0,6 e 0,5 g de matéria seca da parte aérea, respectivamente.

$\mathrm{Na}$ fase 3 , as plantas foram colocadas em canais de $10 \mathrm{~cm}$ de diâmetro, correspondentes a tubos de PVC cortados longitudinalmente e cobertos com papel multicamadas. O espaçamento entre plantas de alface foi de 0,25 x 0,17 m. Os canais possuíam a mesma declividade e a solução nutritiva foi fornecida de modo intermitente, assim como na fase 2. Utilizou-se da solução nutritiva recomendada para alface por Furlani (1998); porém, com 80 e $100 \%$ das concentrações dos macro e micronutrientes, respectivamente. As concentrações foram: 19,2; 139,2; 31,2; 144; 114,0; 32; 41,6; 0,3; 0,02; 2,0; 0,40; 0,06 e $0,06 \mathrm{mg} \mathrm{L}^{-1}$ de $\mathrm{N}-\mathrm{NH}_{4}{ }^{+}, \mathrm{N}-\mathrm{NO}_{3}{ }^{-}, \mathrm{P}, \mathrm{K}, \mathrm{Ca}, \mathrm{Mg}$, $\mathrm{S}, \mathrm{B}, \mathrm{Cu}, \mathrm{Fe}, \mathrm{Mn}$, Mo e $\mathrm{Zn}$, respectivamente. Os reservatórios das soluções nutritivas foram caixas de polietileno com tampa e capacidade para 150 litros. O bombeamento das soluções nutritivas, na cabeceira dos canais, foi realizado uniformemente por bombas hidráulicas submersas (uma por reservatório, por parcela) marca Chosen ${ }^{\circledR}$, modelo Power Head CX-300, com vazão de $1000 \mathrm{~L} \mathrm{~h}^{-1}$, via mangueira. $\mathrm{O}$ acionamento das bombas era controlado por um temporizador, com circulação da solução nutritiva de $7 \mathrm{~h}$ às $18 \mathrm{~h}$, sendo 15 minutos com circulação e 15 minutos sem circulação da solução.

Os tratamentos foram aplicados na fase $3 \mathrm{em}$ épocas distintas. Os tratamentos com solução nutritiva completa e soluções com omissão de $\mathrm{P}$ e Ca foram aplicados no início da fase 3. Quatro dias após foram aplicadas as soluções com omissão de $\mathrm{N}, \mathrm{K}$ e Mg. Portanto, foram avaliados sete tratamentos: $\mathrm{T}_{1}$ - solução completa ( $\left.\mathrm{SC}\right) ; \mathrm{T}_{2}$ - sem nitrogênio (-N); $\mathrm{T}_{3}$ - sem fósforo $(-\mathrm{P}) ; \mathrm{T}_{4}-$ sem potássio $(-\mathrm{K})$; $\mathrm{T}_{5}$ - sem cálcio (-Ca) e $\mathrm{T}_{6}-$ sem magnésio (-Mg).

Para o tratamento - $\mathrm{Ca}$, foi utilizada água deionizada devido à presença de $16 \mathrm{mg} \mathrm{L}^{-1}$ de Ca na água de abastecimento da hidroponia. $\mathrm{O}$ pH de cada solução foi acompanhado semanalmente no início da terceira fase e depois a cada três dias, no período da manhã, e mantido os valores entre 5 e 6. Quando necessário, utilizou-se de ácido sulfúrico para abaixar o $\mathrm{pH}$. A condutividade elétrica (CE) de cada solução foi mantida entre 1,5 e 2,2 dS $\mathrm{m}^{-1}$, utilizando um condutivímetro digital de bolso, modelo DiST4, marca Hanna. Foi avaliado o número de dias para aparecimento dos sintomas iniciais de deficiências de nutrientes para cada tratamento; registro fotográfico dos sintomas, por câmera digital, KODAK EASYHARE C180, desde a sua visualização até o final do ciclo, aos 54 dias da semeadura, quando se fez a colheita. 


\section{Resultados e discussão}

As cultivares de alface 'Oak Leaf Red Pixie', 'Lucy Brown' e 'Verônica' se desenvolveram normalmente, quando cultivadas em solução nutritiva completa (Figura 1).

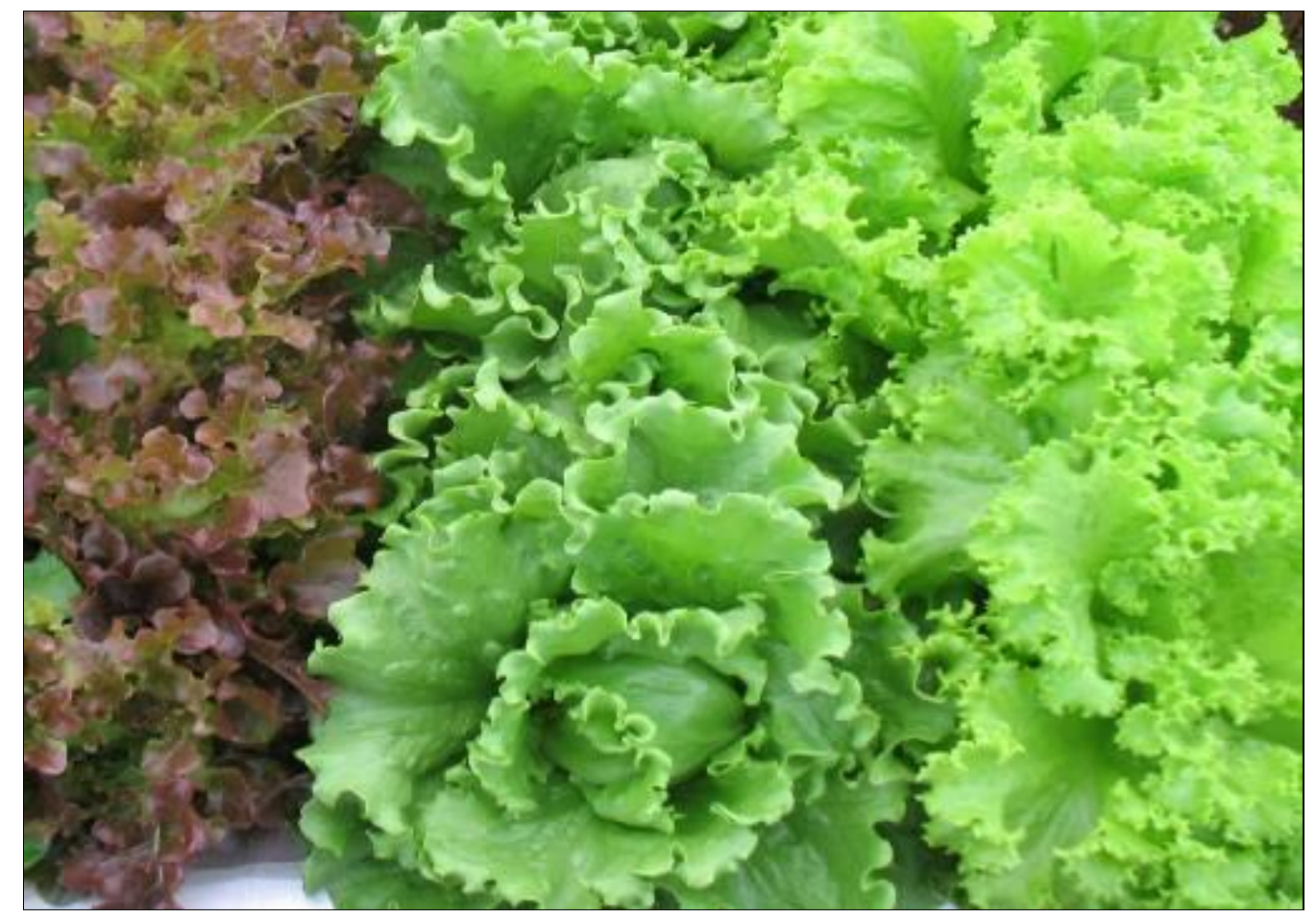

Figura 1 - Alfaces 'Verônica' (A), 'Oak Leaf Red Pixie' (B) e 'Lucy Brown' (C) cultivadas em solução nutritiva completa.

\section{Nitrogênio}

Quatro dias após a omissão de N na solução nutritiva, foi observado o início dos sintomas de deficiência desse nutriente em todas as cultivares. Inicialmente, foi observado descoloração das folhas velhas das três cultivares (Figura 2). Esse sintoma está associado com a menor quantidade de clorofila, que deixa de ser sintetizada ou é degradada (Prado et al., 2007; Barker \& Bryson, 2007). Os sintomas foram observados primeiramente nas folhas velhas devido à alta mobilidade do $\mathrm{N}$ na planta (Hawkesford et al., 2012; Lizcano-Toledo et al., 2018). Quando o suprimento de $\mathrm{N}$ via raizes é insuficiente, o $\mathrm{N}$ das folhas velhas é redistribuído para o tecido mais novo. As proteínas das folhas mais velhas sofrem proteólise, sendo hidrolisadas, e os aminoácidos são redistribuidos para folhas e tecidos novos (LizcanoToledo et al., 2018). Assim, nota-se que a parte central (folhas novas) das plantas estão com coloração mais escura (Figura 3).

Três dias após a visualização da deficiência, a expressão dos sintomas aconteceu diferentemente conforme a cultivar. A clorose nas folhas velhas passou também a ser percebida, ainda em pequena intensidade, nas folhas intermediárias e novas na alface 'Verônica'. Nas folhas velhas das três cultivares, a clorose acentuou-se, observando-se evolução para branqueamento foliar em alface 'Verônica' e 'Lucy Brown' (Figura 4), seguido por necrose (Figura 5), sintomas severos que não foram observados na 'Oak Leaf Red Pixie'. Por outro lado, nessa cultivar, exceto nas folhas mais velhas, foi observado aumento na cor púrpura e praticamente ausência do mosqueado verde-púrpuro característico da cultivar (Figura 6). Provavelmente, os carboidratos que não foram utilizados no metabolismo do $\mathrm{N}$ foram empregados na síntese de antocianina levando ao acúmulo desse pigmento (Taiz \& Zeiger, 2004; Barker \& Pilbeam, 2007; Leghari et al., 2016) nessa cultivar, que tem como característica a pigmentação arroxeada.

Ao final do ciclo, plantas das três cultivares apresentaram crescimento reduzido e as cultivares Verônica e Lucy Brown apresentaram clorose e necrose nos tecidos das folhas velhas. A 'Lucy Brown' não formou cabeça, fato também constatado por Garcia et al. (1982). Portanto, a deficiência de N inibiu o crescimento vegetal, pelo fato de ser constituinte de muitos componentes da célula vegetal, incluindo aminoácidos, hormônios de crescimento e ácidos nucléicos (Taiz \& Zeiger, 2004). Sintomas semelhantes foram observados por Casas \& Casas (1999), Broadley et al. (2000), Rincón (2005) e Almeida et al. (2011). 


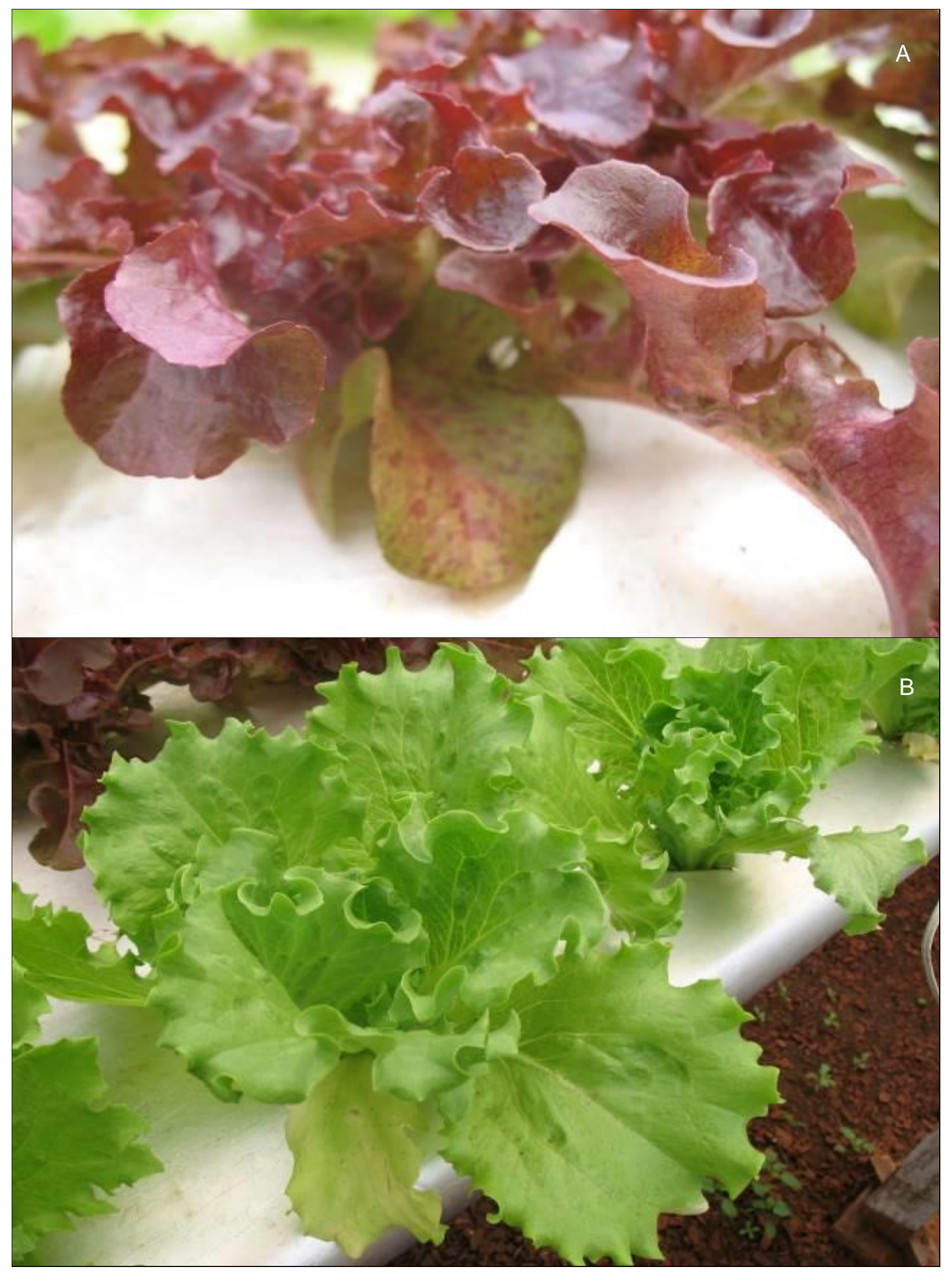

Figura 2 - Início de clorose das folhas velhas em 'Oak Leaf Red Pixie' (A) e 'Lucy Brown' (B) por deficiência de nitrogênio. 


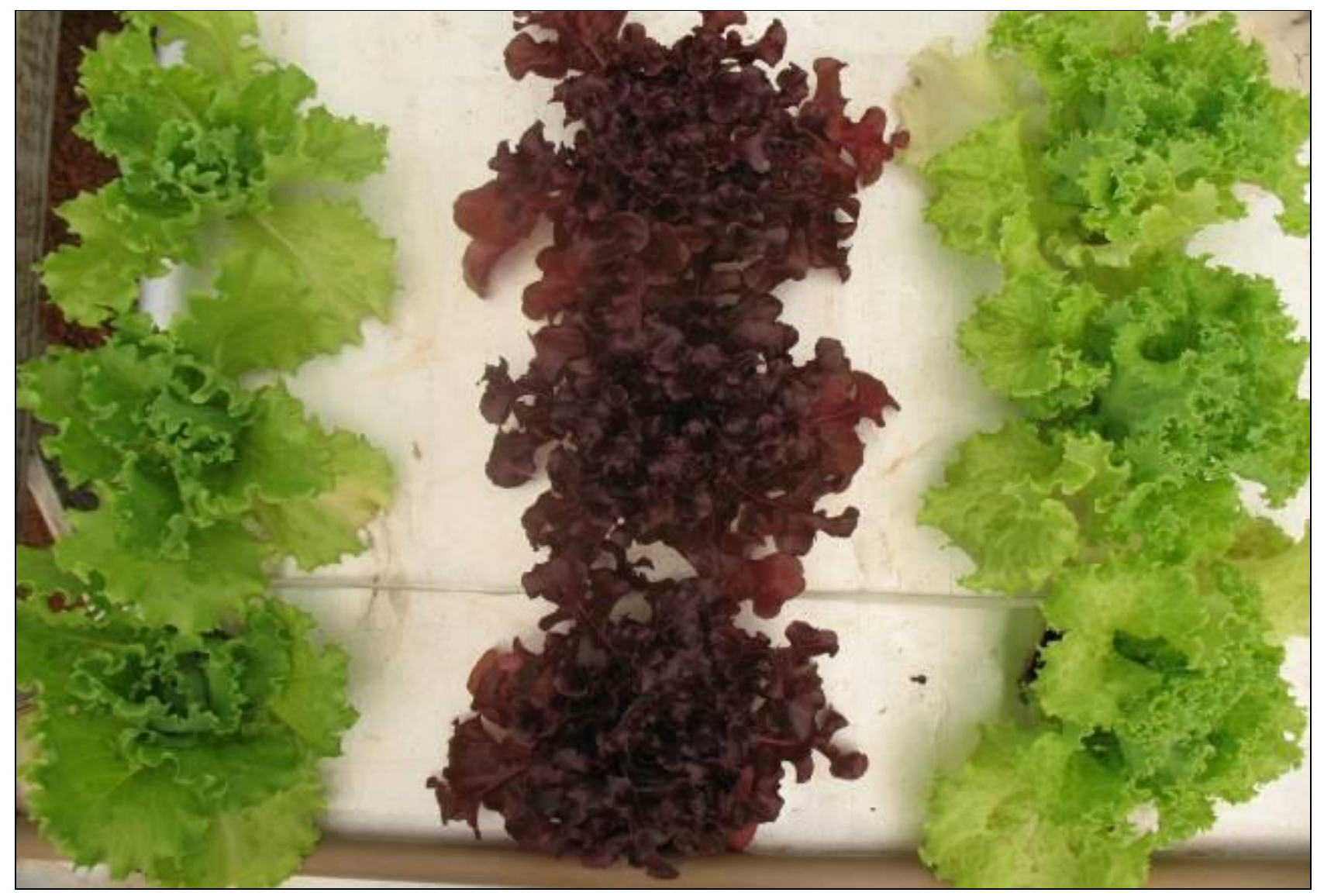

Figura 3 - Caracterização da redistribuição do nitrogênio de folhas velhas para novas após omissão do nitrogênio na solução nutritiva.

\section{Fósforo}

'Verônica' e 'Lucy Brown' apresentaram sintomas de deficiência de $\mathrm{P}$ aos 15 dias após a aplicação do tratamento. Inicialmente, ambas cultivares apresentaram amarelecimento das folhas velhas (Figura 7), resultado da redistribuição do $P$ destas para as folhas novas

A rápida redistribuição do fósforo dos órgãos mais velhos para as mais jovens induziu a planta utilizar o P não metabolizado, localizado no vacúolo das folhas mais velhas (Lizcano-Toledo et al., 2018). As folhas novas permaneceram com a tonalidade de verde característico das cultivares. Com a evolução do sintoma, as folhas das alfaces 'Verônica' e 'Lucy Brown', apresentaram margens marrons e, posteriormente, necrosaram-se (Figura 7). Na 'Oak Leaf Red Pixie' verificou-se aumento da intensidade da cor púrpura, semelhante ao constatado para deficiência de N.

Devido à função que o $P$ exerce na síntese de proteínas, sua falta causa menor crescimento da planta (Sanchez, 2007; Hawkesford et al., 2012). Os sintomas relatados foram também citados por Casas \& Casas (1999), Rincón (2005) e Almeida et al. (2011) que descrevem sintomas adicionais como atraso na maturação e ângulo estreito de inserção das folhas. Rincón (2005) salienta ainda que a deficiência de fósforo em alface manifesta-se com tonalidade de cor púrpura (acúmulo de antocianinas), principalmente nas folhas velhas, iniciando-se na margem e na parte superior das folhas, sendo mais intensa nas nervuras da parte inferior da folha, e quando a deficiência é severa, a formação da cabeça é limitada. Todos os sintomas mencionados não foram observados neste trabalho devido, provavelmente, à reserva de $\mathrm{P}$ que a planta conseguiu acumular durante as fases 1 e 2 , ser necessário para completar o metabolismo relacionado a esses sintomas, quando estava na solução nutritiva completa, porém não foi o suficiente para poder evitar os outros sintomas de deficiência observado neste experimento. $\mathrm{O} P$ atua exercendo função estrutural de diferentes moléculas, fazendo parte de diversos componentes orgânicos, e também como regulador de várias enzimas, sendo importante principalmente na transferência e armazenamento de energia, a qual é utilizada em numerosos processos como as sínteses orgânicas, absorção iônica e fotossíntese (Sanchez, 2007; Maathuis, 2009; Hawkesford et al., 2012).

Os aspectos citológicos e metabólicos mais relevantes em plantas deficientes de $P$ são a ocorrência de núcleos e cloroplastos pequenos, alto conteúdo de açúcares e alta pressão osmótica 
(Malavolta, 2006). Diversos autores relatam redução do crescimento das plantas na omissão de $P$. Contudo, Péret et al. (2014) e Malhotra et al. (2018) afirmam que, em comparação ao crescimento da parte aérea, o crescimento de raízes é menos inibida sob deficiência de fósforo. Segundo Zambolin (1998), a deficiência de $P$ faz com que a planta ofereça menor barreira física à entrada de agente causal como menos lignina e suberina, menor resistência devido à diminuição da produção de defensivos endógenos, alexinas, glicosídeos e alcaloides).

\section{Potássio}

'Verônica' apresentou sintomas de deficiência aos 10 dias após a aplicação do tratamento. O sintoma inicial foi caracterizado por clorose próximo à margem do limbo foliar e manchas marrons. Com a evolução da carência em K, essas manchas aumentaram de tamanho, no sentido da nervura principal, coalescem e atingiram a maior parte da área foliar, cujo tecido, posteriormente, necrosou (Figura 8). Essa necrose é causada pelo acúmulo da putrescina (Mengel, 2007; Prado, 2008; Hawkesford et al., 2012), a qual em nível tóxico induz a oxidação enzimática de compostos fenólicos pelas enzimas peroxidase e polifenol oxidase, o que resulta no escurecimento de tecidos vegetais (Whitehead \& Swardt, 1982; Cui et al., 2020). Sintomas semelhantes foram observados por Casas \& Casas (1999) e Rincón (2005), mas diferentes aos encontrados por Almeida et al. (2011). Faquin (1994), Casas \& Casas (1999) e Rincón (2005) citam, ainda, que quando há deficiência de potássio, as plantas apresentam menor síntese de proteínas e acúmulo de compostos nitrogenados solúveis, como aminoácidos e amidas, além de ter menor acúmulo de nitrato. Apresentam, também, redução significativa no tamanho, com diminuição da matéria seca da parte aérea e raiz, o que não foi confirmado no presente estudo.

A cultivar Oak Leaf Red Pixie apresentou sintomas de deficiência caracterizada por necrose nas folhas mais velhas e coloração roxa intensa em toda a planta.

A cultivar Lucy Brown não apresentou sintoma de deficiência em $\mathrm{K}$, demonstrando ser mais eficiente em utilizar o que absorveu durante a fase 2 (berçário). Isto ocorreu, provavelmente, devido às concentrações de $\mathrm{K}$ vacuolares variarem amplamente. O K mantém o potencial osmótico e o balanço iônico, participando do processo de abertura e fechamento dos estômatos, regulando a transpiração e a entrada de $\mathrm{CO}_{2}$, atuando como um grande influenciador na fotossíntese (Epstein \& Bloom, 2005; Mengel, 2007; Maathuis, 2009; Hawkesford et al., 2012; Hasanuzzaman et al., 2018). Era esperado que devido à essas funções, plantas deficientes em $\mathrm{K}$ se apresentassem murchas nos horários de temperatura elevada, porém que não foi observado neste trabalho.
Em plantas com deficiência de potássio, mudanças químicas ocorrem com acúmulo de carboidratos solúveis, decréscimo no teor de amido e acúmulo de compostos nitrogenados, além da putrescina (Alcázar et al., 2010). A deficiência de $\mathrm{K}$ nem sempre resulta em sintomas visíveis rapidamente. Primeiro ocorre redução no crescimento, "fome oculta", e posteriormente, clorose e necrose nas folhas velhas, devido ao fato dessas folhas suprirem as mais jovens com este cátion (Mengel \& Kirkby, 2001).

\section{Cálcio}

Inicialmente, as plantas de alface cultivadas em solução nutritiva com omissão de cálcio apresentaram progressivo murchamento durante 0 dia. O cálcio é essencial para manter a integridade estrutural e funcional das membranas plasmáticas e da parede celular (Malavolta, 2006; Maathuis, 2009; Hawkesford et al., 2012). Quando há deficiência, as membranas permitem o extravazamento do conteúdo citoplasmático (Mengel \& Kikby, 2001; Malavolta, 2006).

Aos 15 dias após a aplicação do tratamento foi observada a desordem fisiológica denominada "tip burn" em 'Verônica' e em 'Lucy Brown'. O sintoma caracteriza-se por necrose dos tecidos da margem de folhas jovens e ápice da planta (Figura 9). Nas figuras 10 e 11 observa-se a evolução do sintoma. A cv. Oak Leaf Red Pixie não apresentou "tip burn". A resposta diferenciada das cultivares pode ser observada na Figura 12.

Esse sintoma é descrito na literatura como deficiência localizada de cálcio (Termohlen \& Hoeven, 1966; Thibodeau \& Minotti, 1969; Cox, 1980; Collier \& Tibbits, 1982; Barta \& Tibbitts, 2000), devido ao transporte insuficiente para os órgãos de crescimento, pela baixa absorção nas raízes e nula redistribuição (Epstein \& Bloom, 2005; Pilbeam \& Morley, 2007; Hawkesford et al., 2012; Hocking et al., 2016). Sintomas semelhantes foram observados por Casas \& Casas (1999), Rincón (2005) e Almeida et al. (2011). Em função dos diferentes fatores que afetam a absorção e a distribuição de cálcio no interior das plantas, a necrose dos tecidos da margem de folhas poderá ocorrer mesmo quando se cultiva em solo ou solução nutritiva com elevada disponibilidade de cálcio.

Nesse tratamento com omissão de $\mathrm{Ca}$, também foi observada diminuição, escurecimento, podridão mole do caule e morte de raízes (Figura 13), com um aspecto gelatinoso. Olle \& Bender (2009) e Leitão et al. (2019) relatam que o cálcio está envolvido na divisão celular e o não atendimento das exigências desse nutriente nas plantas provoca inibição da extensão celular, sobretudo as radiculares, que são as primeiras a cessar o crescimento, o que foi constatado também por Pacheco et al. (2007). Sob deficiência severa de $\mathrm{Ca}$ ocorre a desintegração da membrana e a perda de compartimentos celulares (Hocking et al., 2016). 


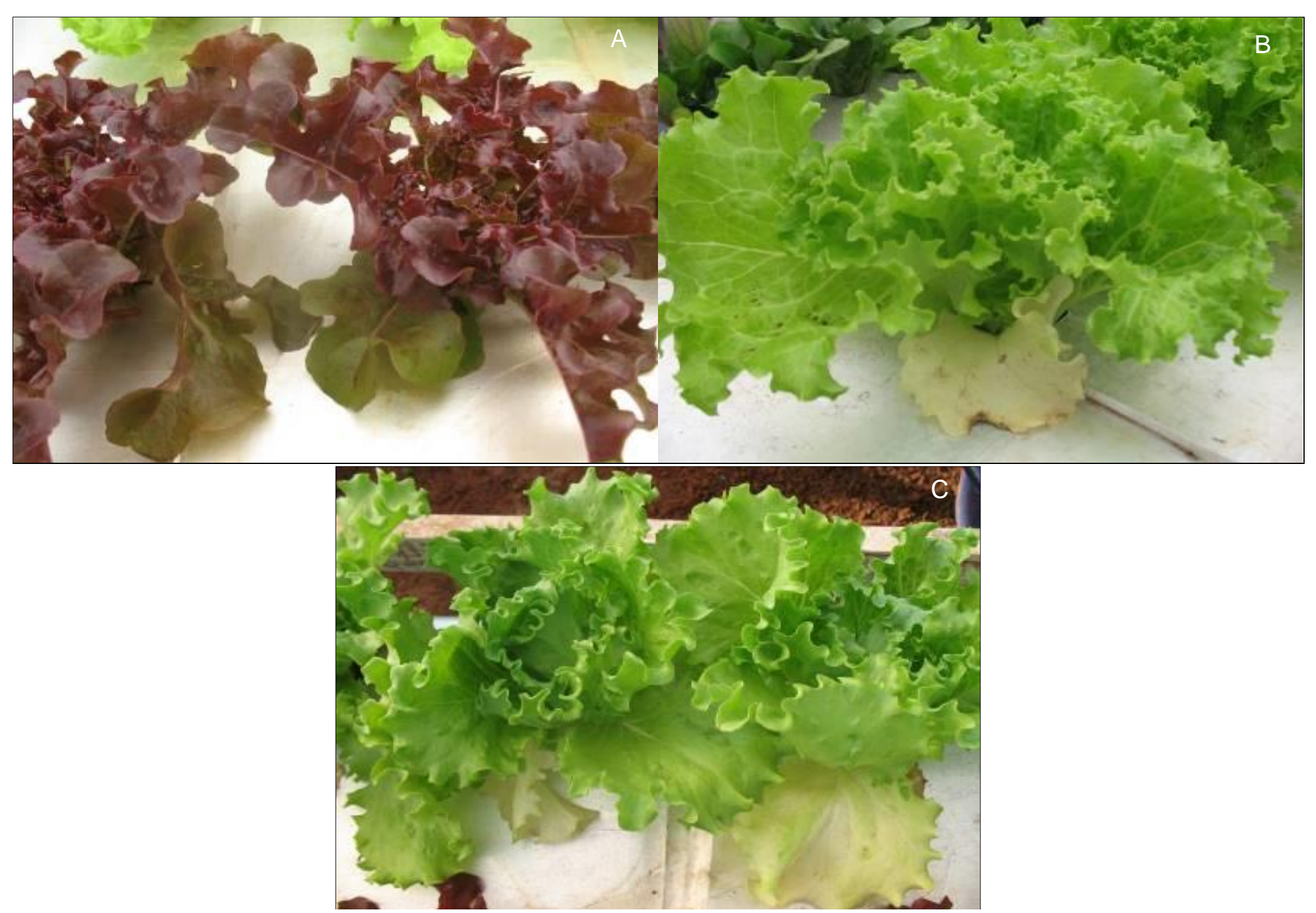

Figura 4 - Evolução da clorose nas cultivares de alface 'Oak Leaf Red Pixie' (A), 'Verônica' (B) e 'Lucy Brown' (C) por deficiência de nitrogênio. 


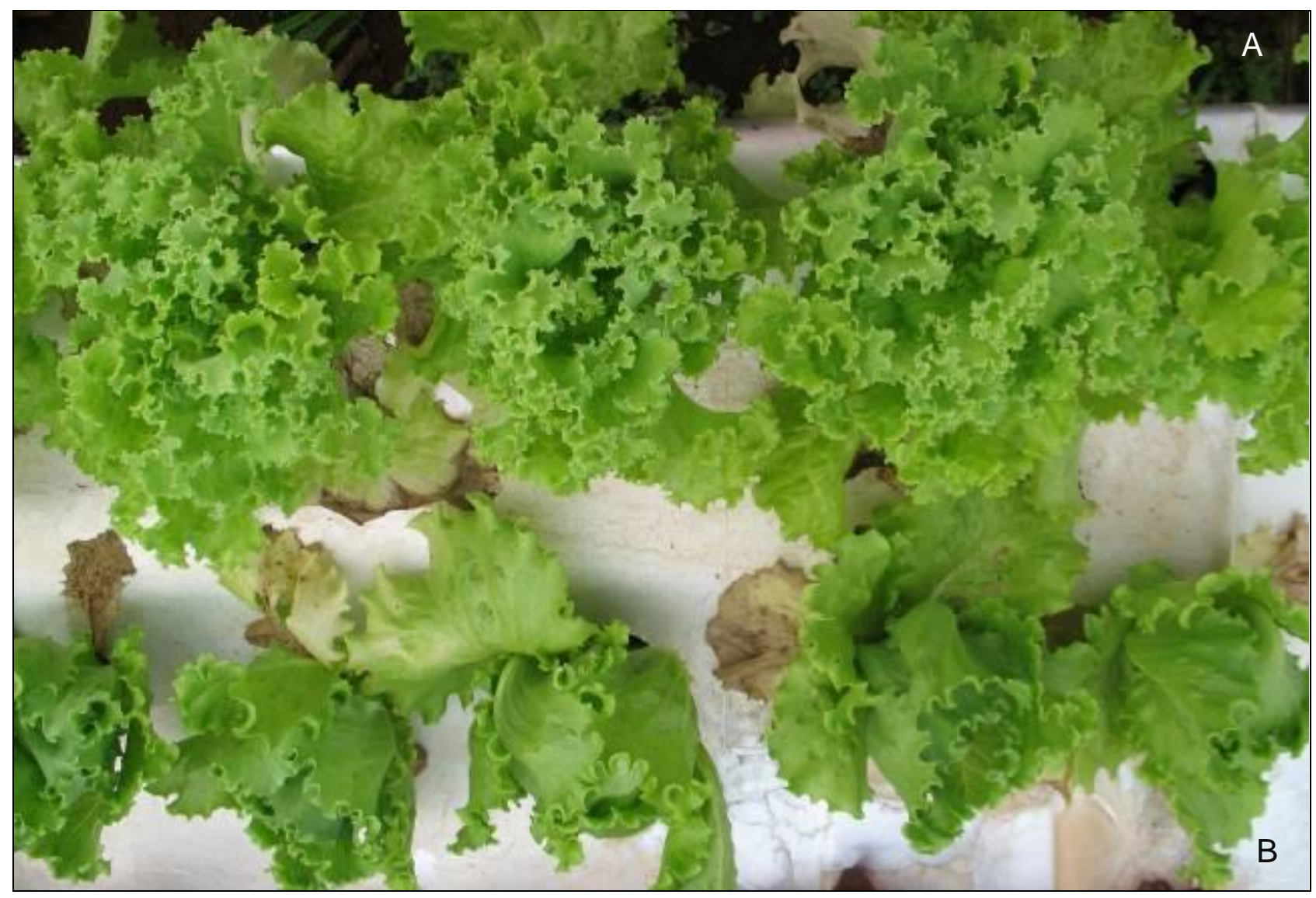

Figura 5 - Necrose foliar causada pela deficiência severa de nitrogênio em 'Verônica' (A) e 'Lucy Brown' (B) por deficiência de nitrogênio.

\section{Magnésio}

'Verônica' e 'Lucy Brown' apresentaram sintomas de deficiência de $\mathrm{Mg}$ aos 10 e 12 dias após a aplicação do tratamento, respectivamente. Inicialmente, observou-se clorose internerval conforme normalmente é reportado à deficiência de $\mathrm{Mg}$. Houve descolaração de parte do tecido de folhas velhas, mantendo-se as nervuras verdes (Figura 14). Com a persistência da omissão, o sintoma se espalha por todo o limbo (Figura 15), ocorre clorose quase generalizada (Figura 16). Na sequência, necrose foliar. Sintomas semelhantes foram observados por Casas \& Casas (1999), Rincón (2005) e Almeida et al. (2011). 'Oak Leaf Red Pixie não apresentou sintomas de deficiência em Mg.

$\mathrm{O} M g$ é constituinte da clorofila, e nesse composto está $20 \%$ do seu total na planta. O restante acompanha o $\mathrm{Ca}$ na formação da parede celular (Prado, 2008; Gerendás \& Führs, 2013). Esse nutriente é essencial para os cloroplastos, sendo o átomo central da molécula de clorofila, sendo a quantidade dessa influenciada por variações no teor de Mg no citossol e no cloroplasto (Ding et al., 2006; Hauer-Jákli \& Tränkner, 2019). Assim, na deficiência de $\mathrm{Mg}$, há diminuição na síntese de clorofila e consequentemente, na taxa fotossintética. 


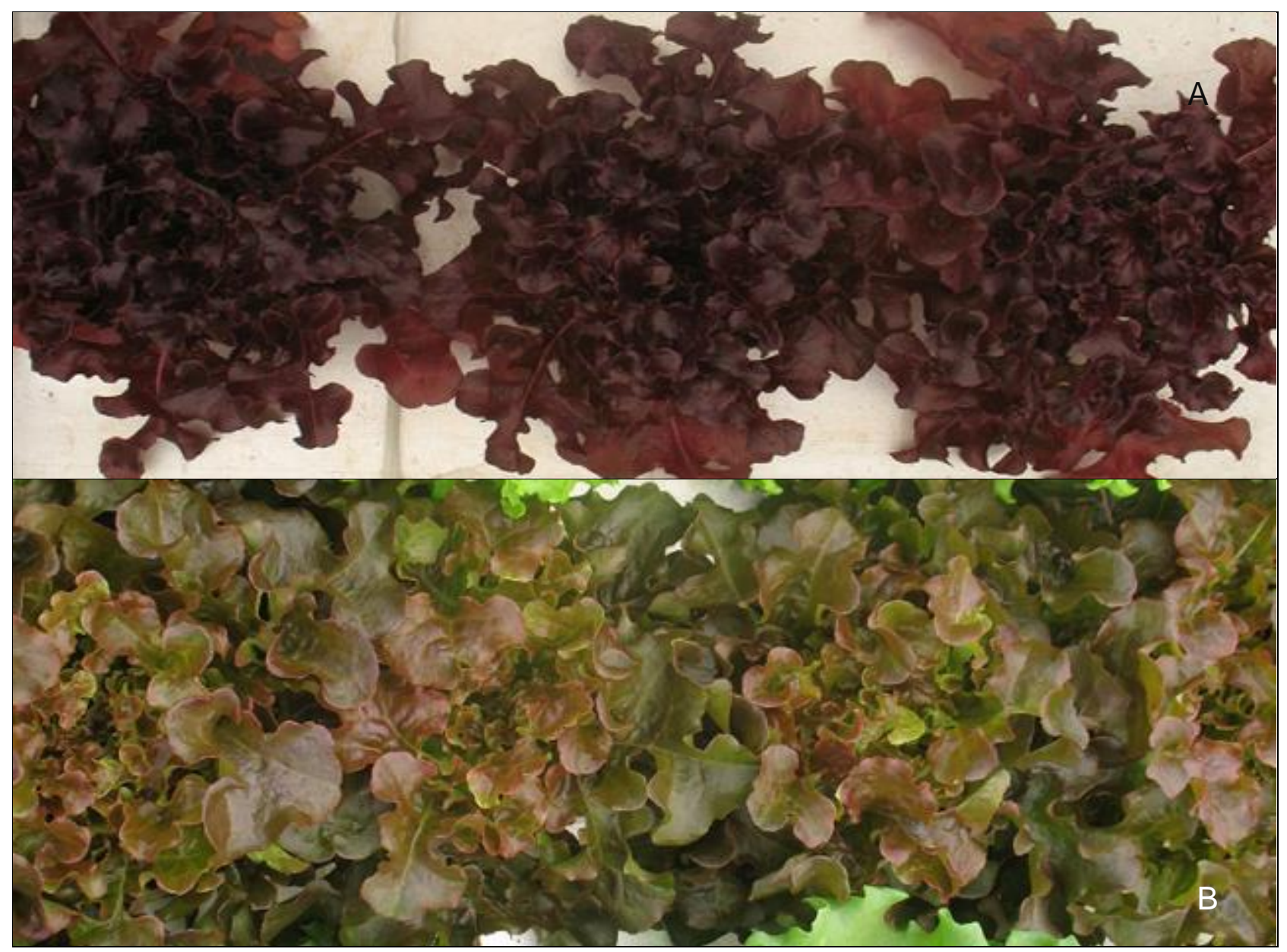

Figura 6 - Comparativo da coloração das folhas da alface quando em deficiência de nitrogênio $(A)$ e cor característica (B) quando cultivada com solução completa. 


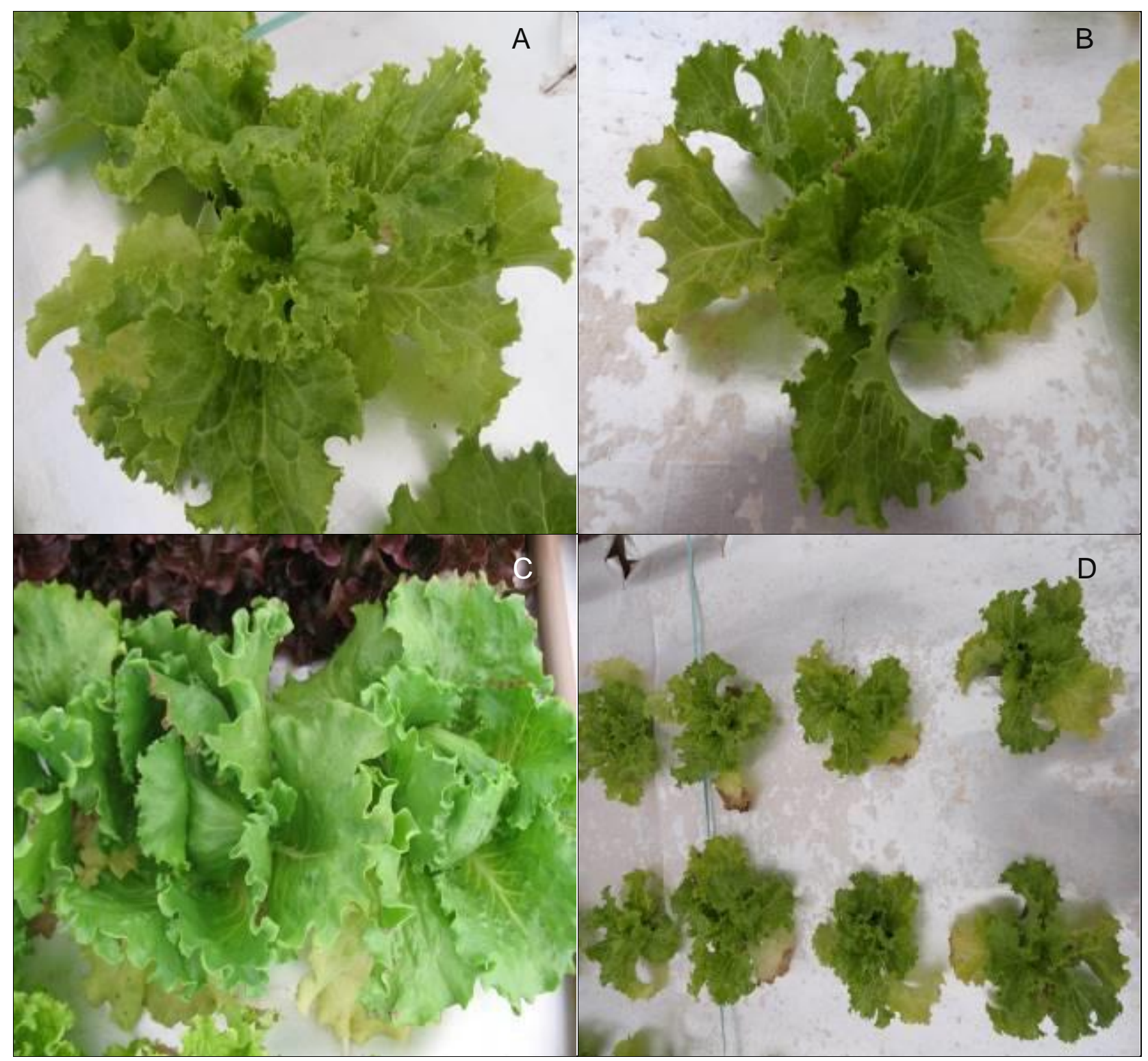

Figura 7 - Evolução da deficiência de fósforo em alface 'Verônica' e 'Lucy Brown': clorose inicial (A) e acentuada $(B$ e $C$ ) das folhas velhas seguida por necrose marginal (D). Folhas mais jovens com coloração verde preservada. 


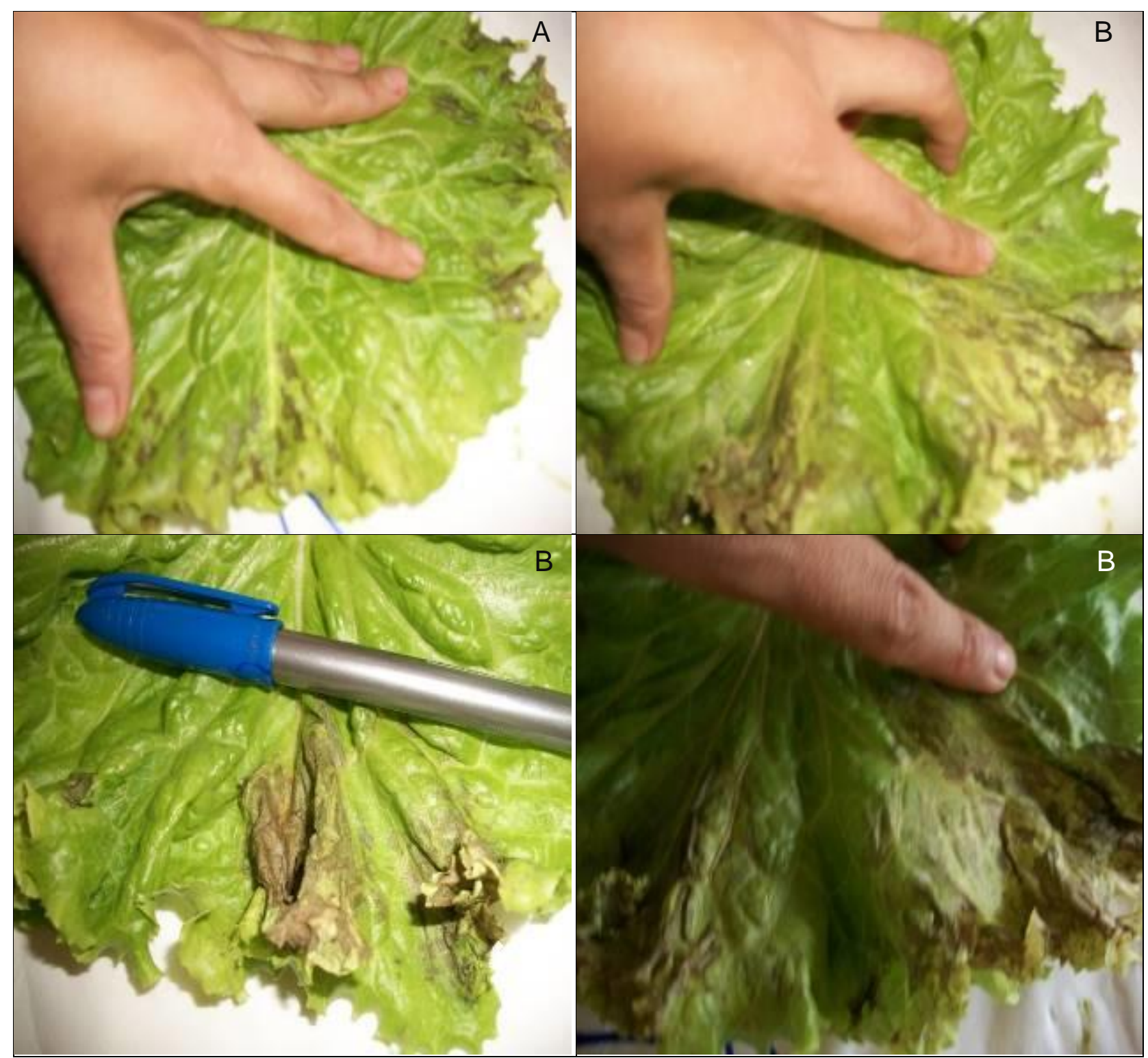

Figura 8 - Sintoma inicial (A) e severo (B) de deficiência de potássio na cultivar Verônica. 

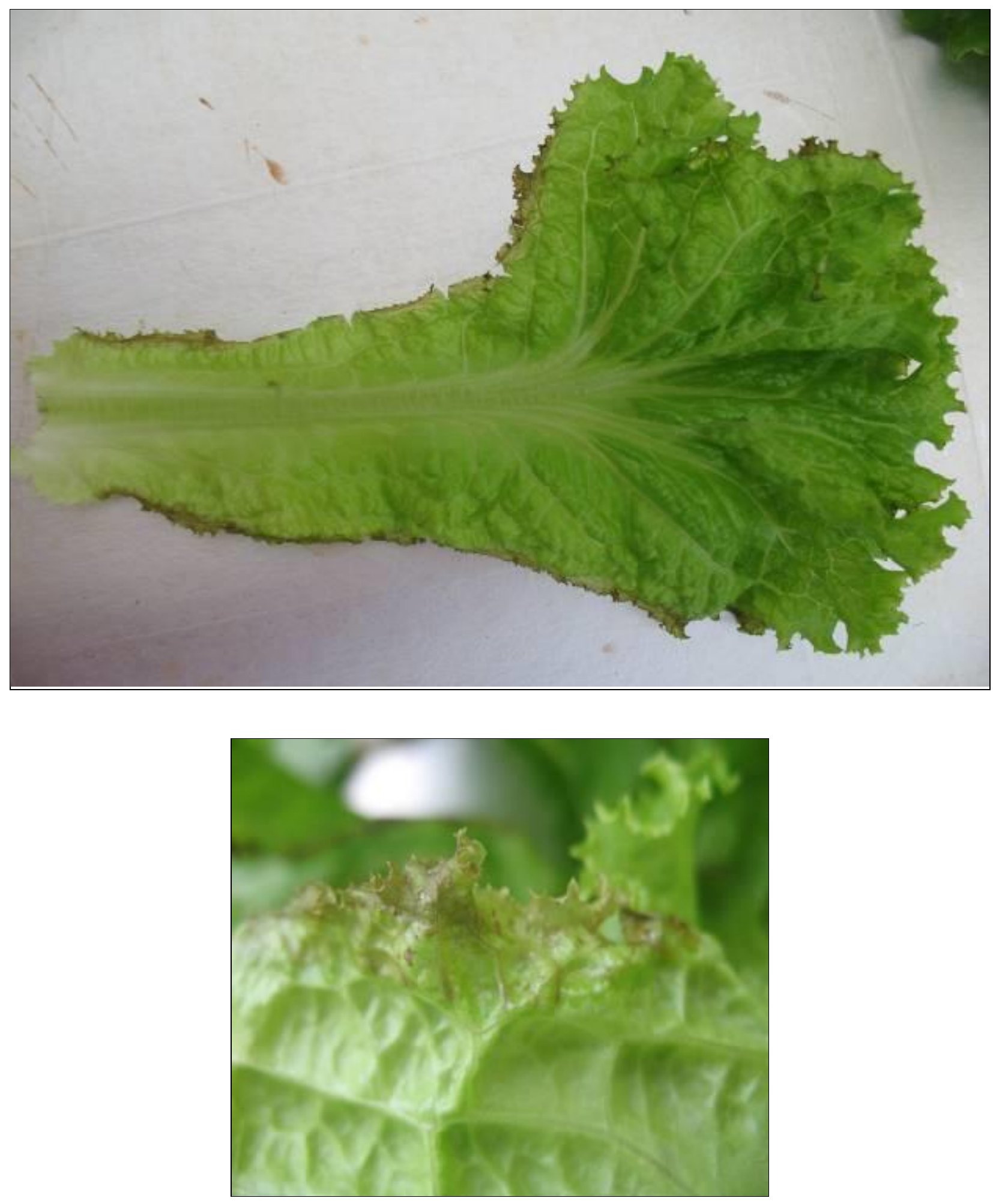

Figure 9 - Sintoma inicial de necrose foliar (tip burn) em folha de alface. 


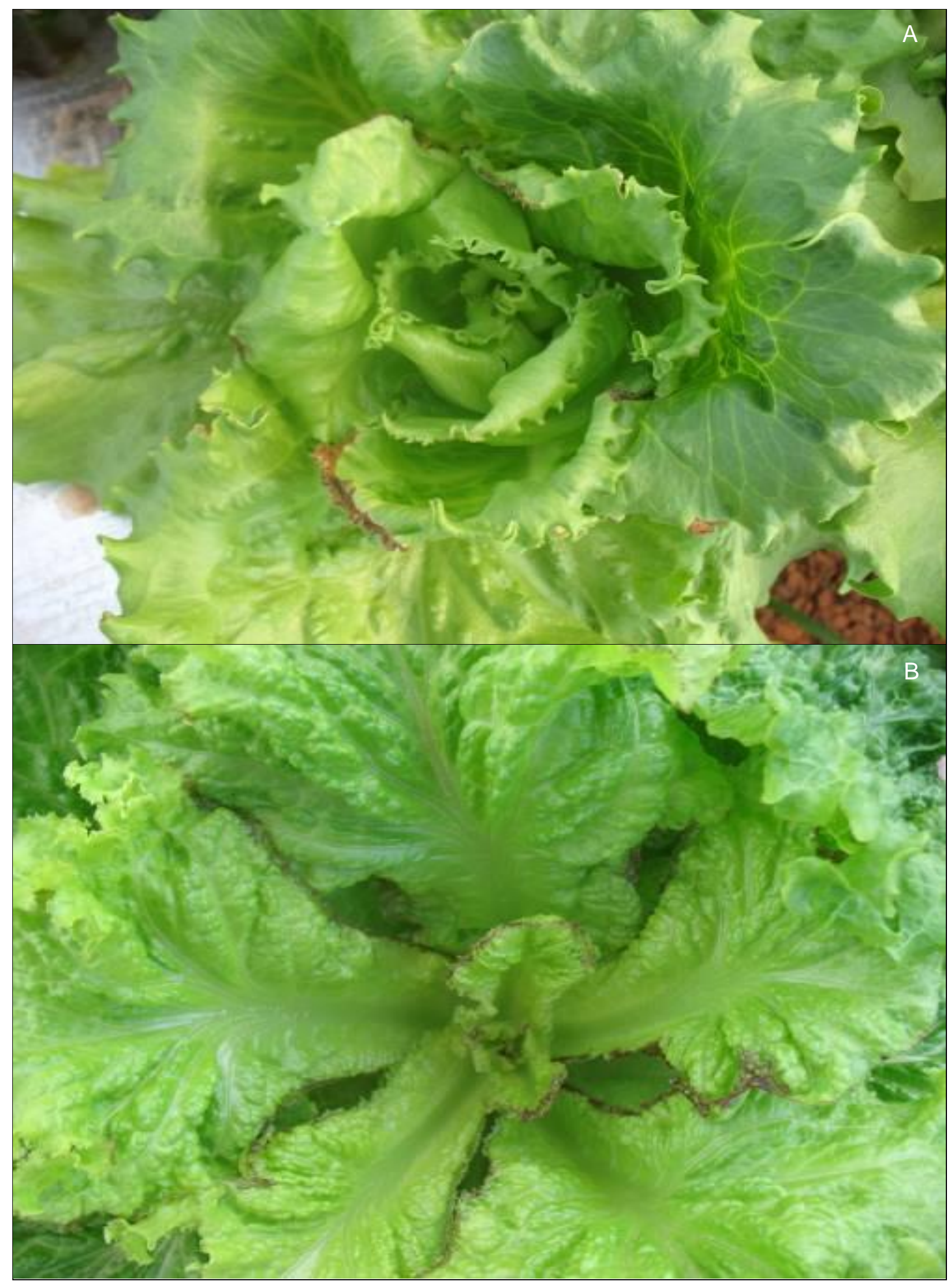

Figure 10 - Sintomas iniciais de necrose foliar em alface 'Lucy Brown' (A) e 'Verônica' (B) em razão da omissão de cálcio na solução nutritiva. 


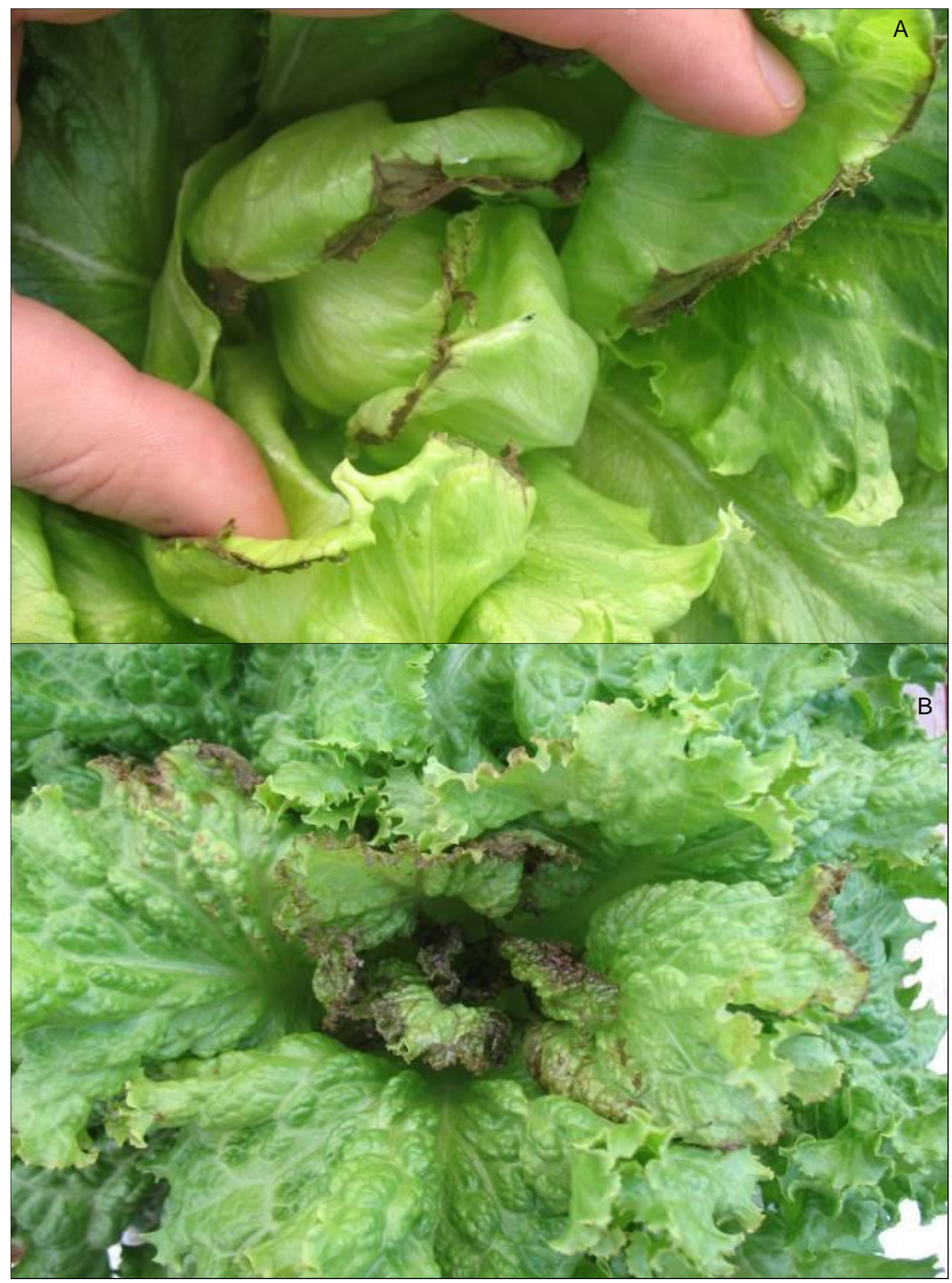

Figura 11 - Sintomas severos de necrose foliar em alface 'Lucy Brown' (A) e 'Verônica' (B) em razão da persistência na omissão de cálcio na solução nutritiva. 


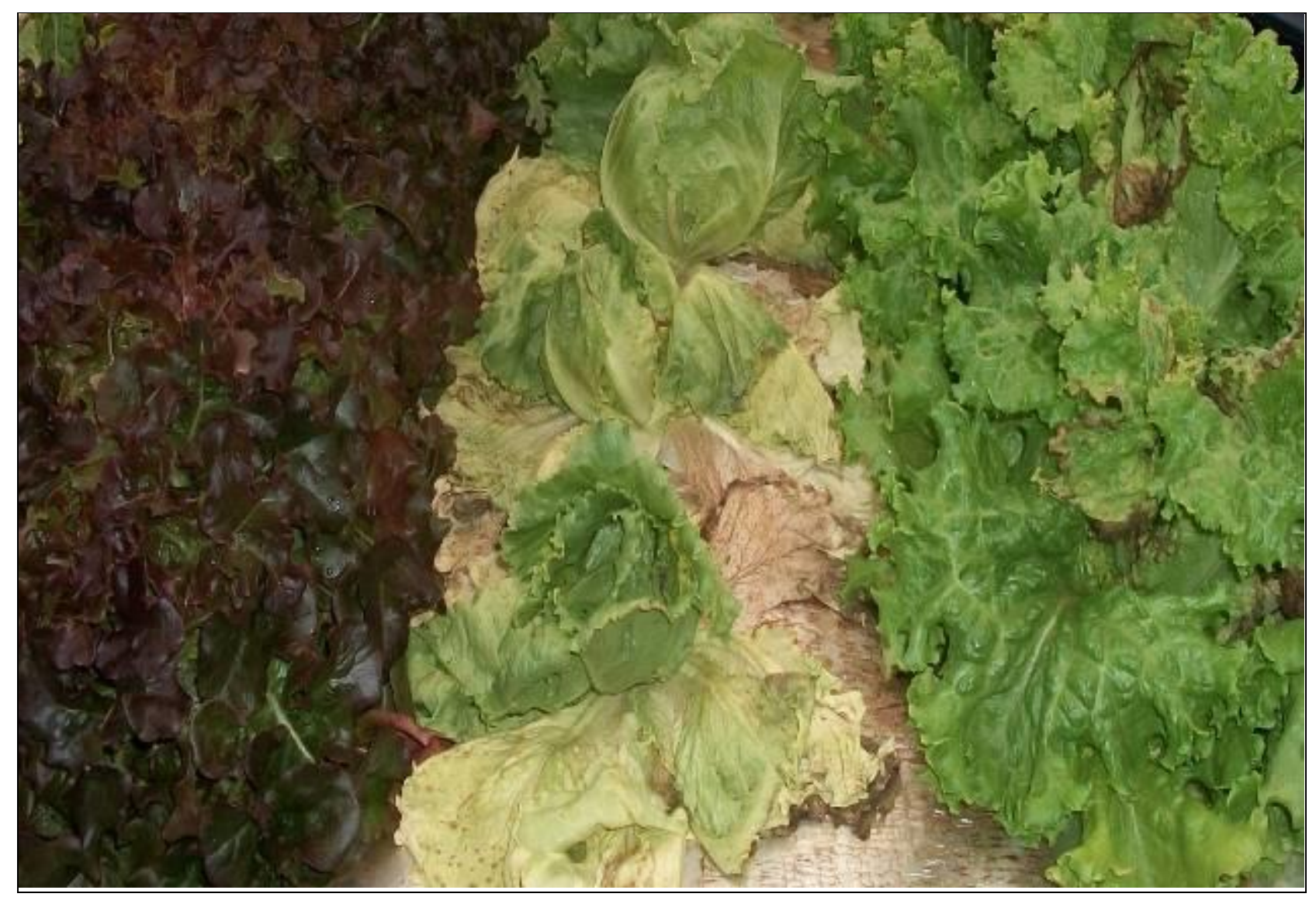

Figure 12 - Resposta diferenciada de cultivares quanto à intensidade de sintoma de deficiência de cálcio quando da omissão do nutriente na solução nutritiva.

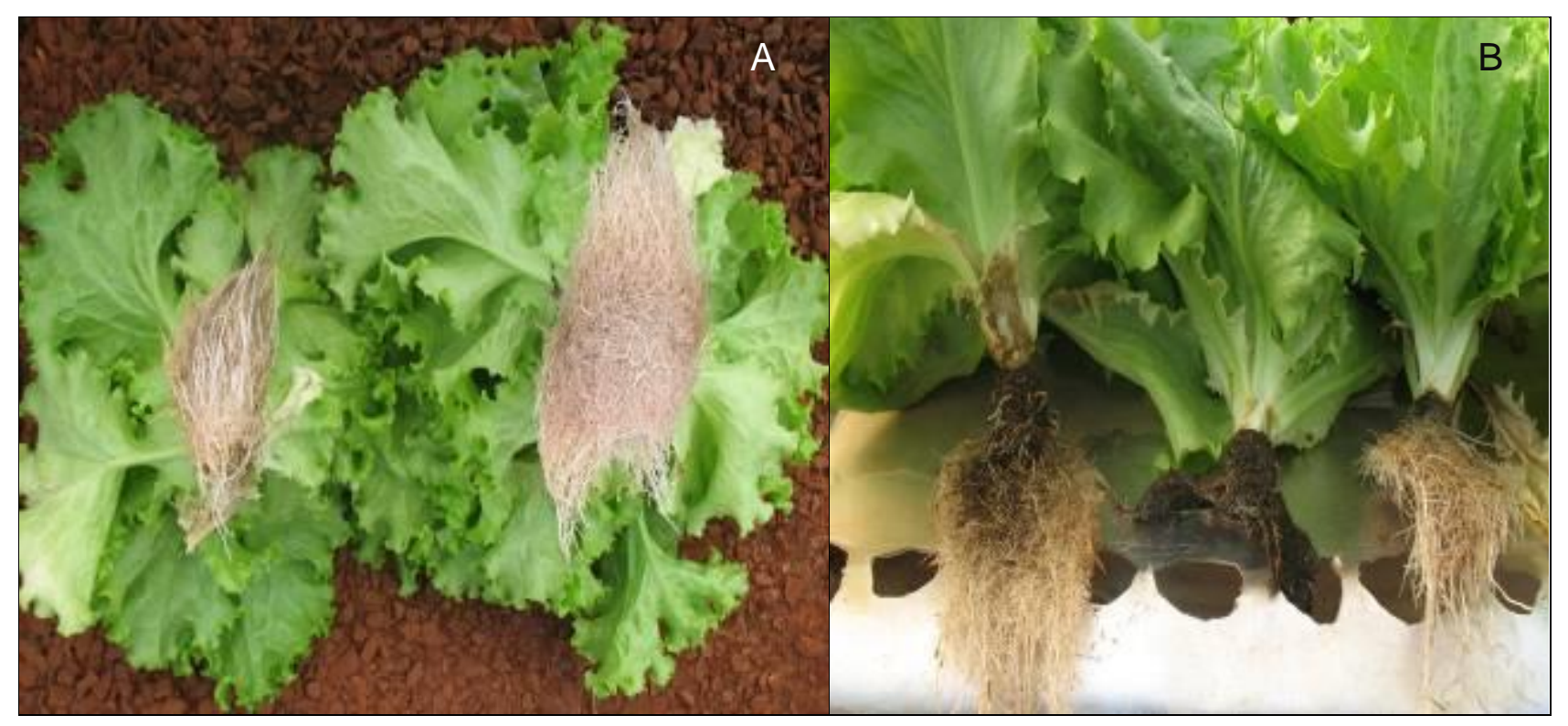

Figure 13 - Sistema radicular em fase inicial (A) e final (B) da desordem fisiológica por deficiência de cálcio em alface. 


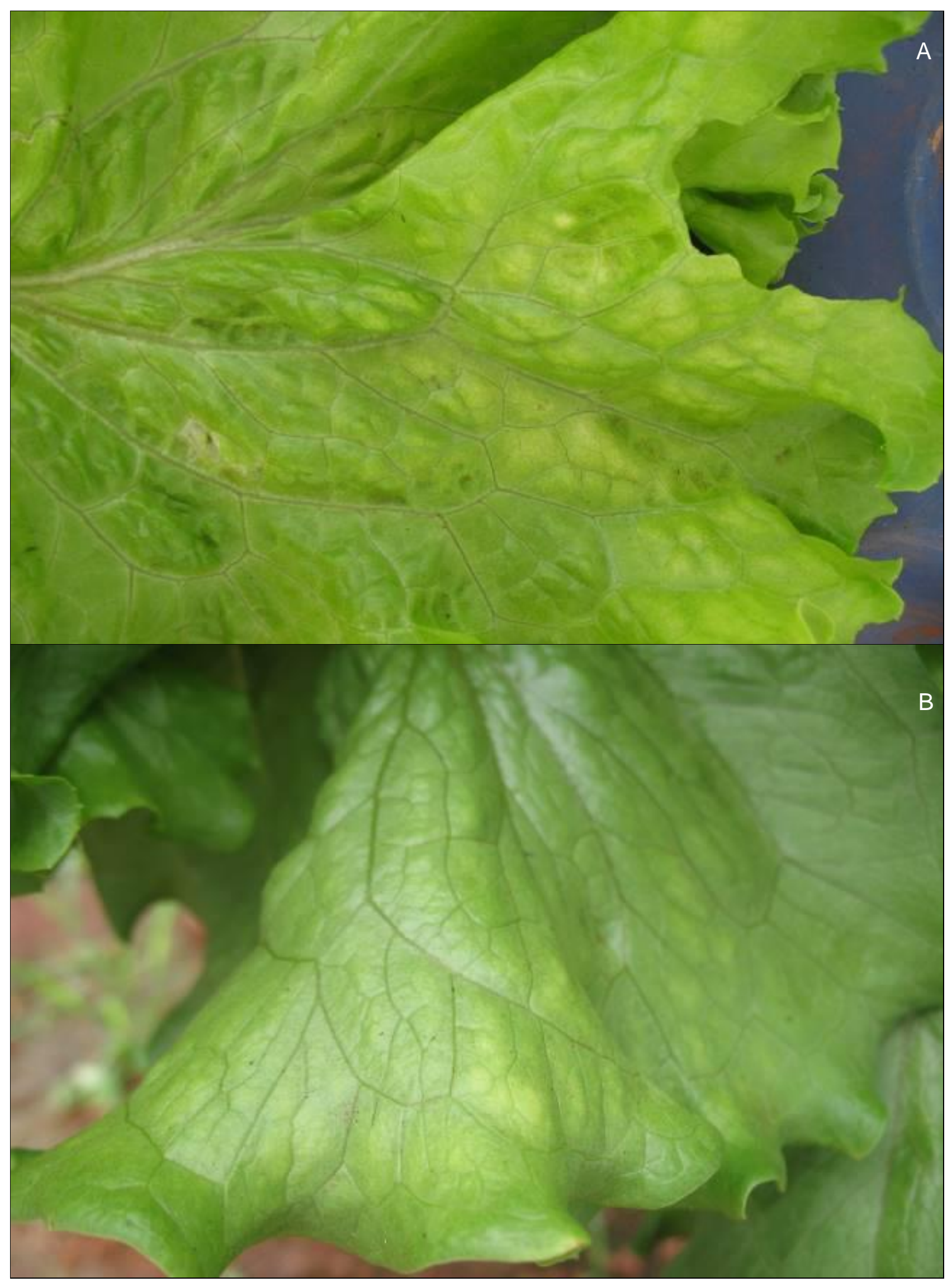

Figura 14 - Sintoma inicial de deficiência de magnésio em alface 'Verônica' (A) e em 'Lucy Brown' (B). 


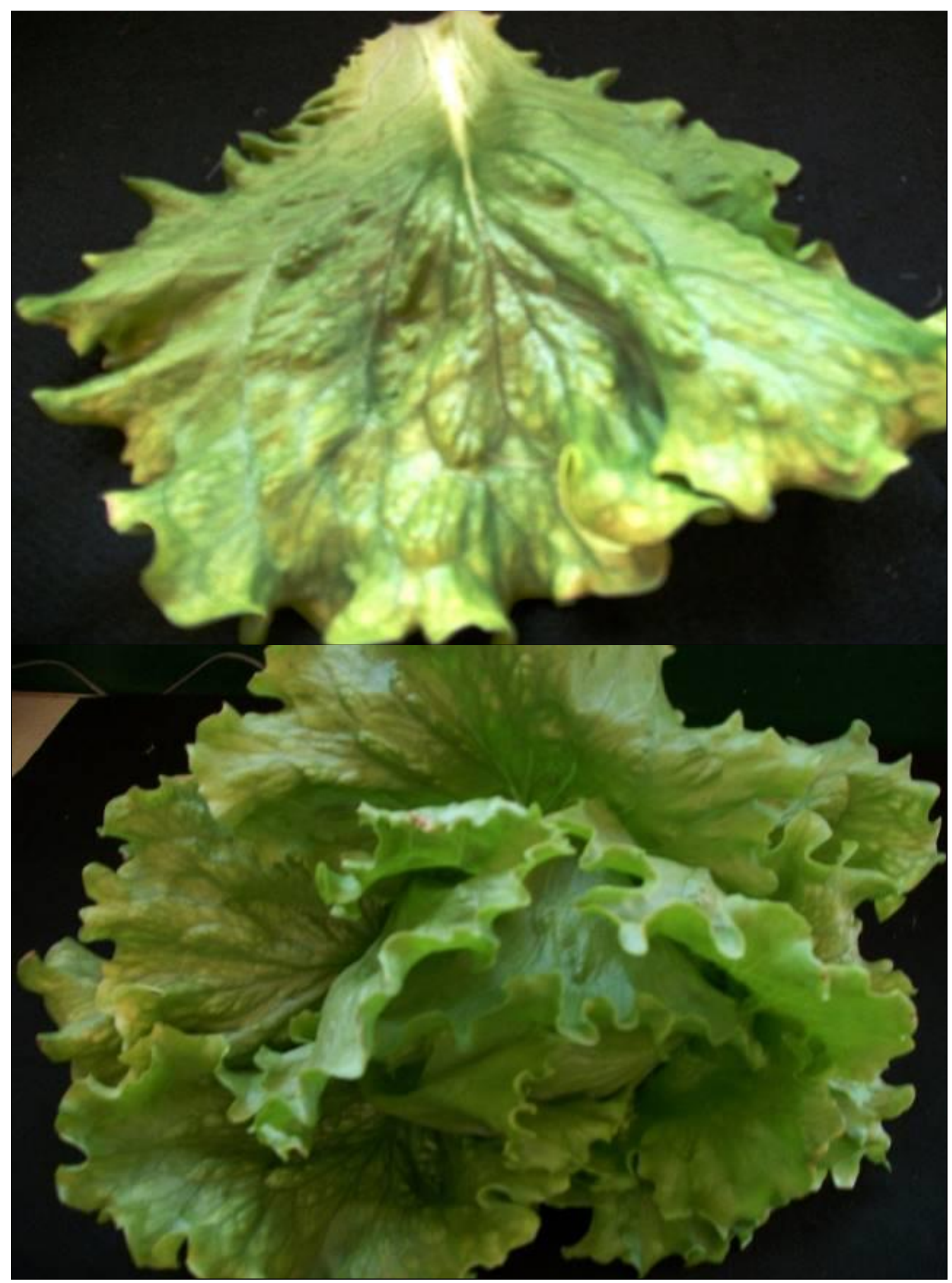

Figura 15 - Sintoma generalizado, em intensidade intermediária, da deficiência de magnésio em alface. 


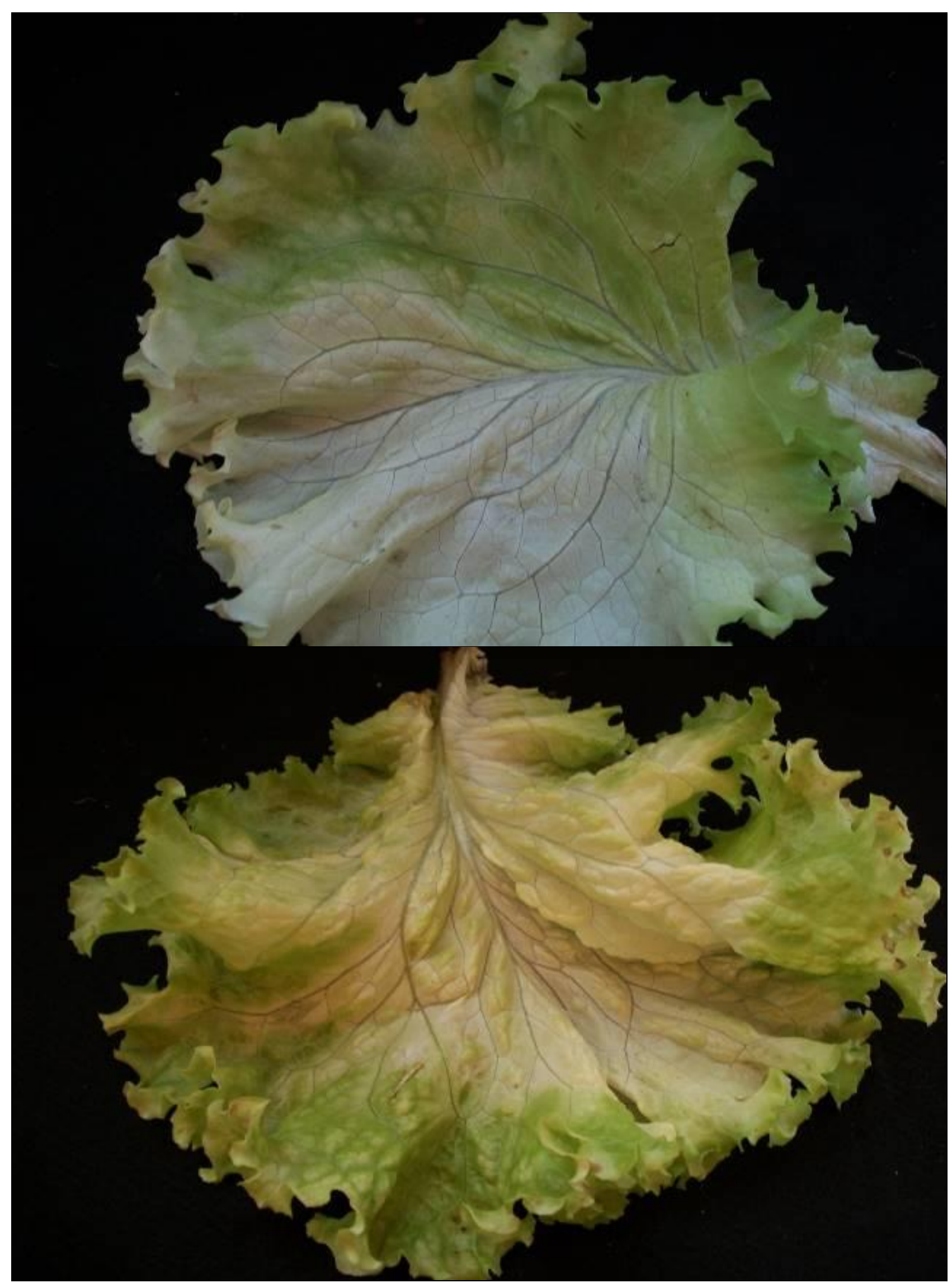

Figura 16 - Clorose avançada e intensa do limbo foliar em decorrência da deficiência severa de magnésio em alface. 


\section{Conclusão}

Nitrogênio é o nutriente que primeiro desencadeou sintomas de deficiência.

A omissão de nutrientes, especialmente para $\mathrm{N}, \mathrm{K}, \mathrm{Ca}$ e $\mathrm{Mg}$, mesmo em sua condição inicial, compromete o aspecto comercial da alface.

\section{Referências}

Alcázar R, Altabella T, Marco F, Bortolotti C, Reymond $\mathrm{M}$, Koncz C, Carrasco P, Tiburcio AF (2010) Polyamines: molecules with regulatory functions in plant abiotic stress tolerance. Planta 231(6):1237-1249.

Almeida TBF; Prado RM; Puga AP; Correia MAR; Barbosa JC (2011) Avaliação nutricional da alface cultivada em soluções nutritivas suprimidas de macronutrientes. Revista Biotemas 24(2):27-36.

Barker AV, Bryson GM (2007) Nitrogen. In: Barker AV, Pilbeam DJ (eds). Handbook of plant nutrition. Boca Raton, FL: Taylor \& Francis Group. p. 21-50.

Barker AV, Pilbeam DJ (2007) Introduction. In: Barker AV, Pilbeam DJ. (eds). Handbook of plant nutrition. Boca Raton, FL: Taylor \& Francis Group. p. 3-18.

Barta DJ, Tibbitts TW (2000) Calcium localization and tipburn development in lettuce leaves during early enlargement. Journal of the American Society for Horticultural Science 125(3):294-298.

Broadley MR, Escobar-Gutierrez AJ, Burns A, Burns IG (2000) What are the effects of nitrogen deficiency on growth components of lettuce? Research 147(3):519-526.

Casas AC, Casas EB (1999) Análisis de suelo agua planta y su aplicación en la nutrición de cultivos hortícolas en la zona penínsular, 2 ed. Almería: Caja Rural de Almería. 239p.

Collier G, Tibbitts T (1982) Tipburn of lettuce. Horticultural Reviews 4:49-65.

Cox E (1980) Growth of lettuce roots and its possible relationship to tipburn development. Horticultural Research 20(2):61-66.

Cui J, Pottosin I, Lamade E, Tcherkez G (2020) What is the role of putrescine accumulated under potassium deficiency? Plant, Cell \& Environment 2020:1-17.

Ding Y, Luo W, Xu G (2006) Caracterization of magnesium nutrition and interaction of magnesium and potassion in rice. Annals of Applied Biology 149(2):111-123.
Epstein E, Bloom AJ (2005) Mineral nutrition of plants: principles and perspectives. 2nd edition Sinauer Associates, Inc. Sunderland, Mass. 400p.

Faquin V (1994). Nutrição mineral de plantas. Lavras: ESAL-FAEPE. 227p.

Furlani PR (1998) Instruções para o cultivo de hortaliças folhosas pela técnica de hidroponia-NFT. Campinas: IAC, 30p. (Boletim Técnico, 168).

Garcia LLC (1982) Absorção de macro e micronutrientes e sintomas de carência de macronutrientes em alface (Lactuca sativa L.), cv. Brasil 48 e Clause's Aurelia. Piracicaba: Esalq-USP. 78p. (Dissertação de Mestrado em Solos e Nutrição de Plantas).

Gerendás J, Führs H (2013) The significance of magnesium for crop quality. Pant Soil 368(1-2):101128.

Hasanuzzaman M, Borhannuddin Bhuyan MHM, Nahar K, Shahadat Hossain M, Al Mahmud J, Shahadat Hossen M, Masud AAC, Moumita, Fujita M (2018) Potassium: a vital regulator of plant responses and tolerance to abiotic stresses. Agronomy 8(3):31.

Hauer-Jákli M, Tränkner M (2019). Critical leaf magnesium thresholds and the impact of magnesium on plant growth and photo-oxidative defense: a systematic review and meta-analysis from 70 years of research. Frontiers in Plant Science 10:766.

Hawkesford M, Horst W, Kichey T, Lambers H, Schjoerring J, Skrumsager Moller I, White P (2012) Function of macronutrients. In: Marschner P. (ed). Marschner's mineral nutrition of higher plants. Third Edition Oxford: Elsevier Ltd. p. 135-178.

Hocking B, Tyerman SD, Burton RA, Gilliham M (2016) Fruit calcium: transport and physiology. Frontiers in Plant Science 7:569.

Leghari SJ, Wahocho NA, Laghari GM, Laghari AH, Bhabhan GM, Talpur KH, Bhutto TA, Wahocho SA, Lashari AA (2016) Role of nitrogen for plant growth and development: a review. Advances in Environmental Biology 10(9):209-218.

Leitão N, Dangeville $P$, Carter R, Charpentier M (2019) Nuclear calcium signatures are associated with root development. Nature Communications 10: 4865.

Lizcano-Toledo R, Saavedra-Mora D, SánchezTrujillo YD, Prado RM, Nowaki RHD (2018) Diagnóstico nutricional de cultivos en Colombia. La Angostura, Colombia: Servicio Nacional de Aprendizaje SENA. 142p. 
Maathuis FJM (2009) Physiological functions of mineral macronutrients. Current Opinion in Plant Biology 12(3):250-258.

Malavolta E (2006) Manual de nutrição de plantas. São Paulo: Editora Ceres. 638p.

Malhotra H, Vandana, Sharma S, Pandey R (2018) Phosphorus nutrition: plant growth in response to deficiency and excess. In: Hasanuzzaman M, Fujita M, Oku H, Nahar K, Hawrylak-Nowak B (eds). Plant nutrients and abiotic stress tolerance. New Delhi, India: Springer Nature Singapore. p. 171-190.

Mengel K (2007) Potassium. In: Barker AV; Pilbeam DJ (eds). Handbook of plant nutrition. Boca Raton, FL: Taylor \& Francis Group. p. 91-120.

Mengel K, Kirkby EA (2001) Principles of plant nutrition. 5 ed. Bern: International Potash Institute. $868 p$.

Nafiu AK, Abiodun MO, Okpara IM, Chude VO (2012) Soil fertility evaluation: a potential tool for predicting fertilizer requirement for crops in Nigeria. African Journal of Agricultural Research 7(47):6204-6214.

Ohse S, Dourado Neto D, Manfron PA, Santos OS (2001) Qualidade de cultivares de alface produzidos em hidroponia. Scientia Agrícola 58(1):181-185.

Olle M, Bender I (2009) Causes and control of calcium deficiency disorders in vegetables: a review. Journal of Horticultural Science \& Biotechnology 84(6):577-584.

Pacheco DD, Dias MSC, Antunes PD, Ribeiro DP, Silva JJC, Pinho DB (2007) Nutrição mineral e adubação do morangueiro. Informe Agropecuário. Morango: conquistando novas fronteiras. Belo Horizonte 28(236): 40-49.

Péret B, Desnos T, Jost R, Kanno S, Berkowitz O, Naussame L (2014) Root architecture responses: in search of phosphate. Plant Physiology 166(4):17131723.

Pilbeam DJ, Morley PS (2007) Calcium. In: Barker AV, Pilbeam DJ (eds). Handbook of plant nutrition. Boca Raton, FL: Taylor \& Francis Group. p. 121-144. Prado RM (2008) Nutrição de plantas. São Paulo: Editora UNESP. 417p.
Prado RM, Romualdo LM, Rozane DE (2007) Omissão de macronutrientes no desenvolvimento e no estado nutricional de plantas de sorgo (cv. BRS 3010) cultivadas em solução nutritiva. Científica 35(2):122-128.

Rincón LS (2005) La fertirrigación de la lechuga iceberg. Murcia: INIA-IMIDA, 183p.

Sala FC, Costa CP (2012) Retrospectiva e tendência da alfacicultura brasileira. Horticultura Brasileira 30(2):187-194.

Sanchez CA (2007) Phosphorus. In: Barker AV, Pilbeam DJ (eds). Handbook of plant nutrition. Boca Raton, FL: Taylor \& Francis Group. p. 51-90.

Silva MAC (2006) Métodos de avaliação do estado nutricional para 0 algodoeiro no Centro-Oeste do Brasil. Jaboticabal: UNESP-FCAV. 75p. (Tese Doutorado).

Taiz L, Zeiger E (2004) Fisiologia vegetal. 3 ed. Porto alegre: Artmed, 719p.

Termohlen G, Hoeven A (1966) Tipburn symptoms in lettuce. Acta Horticulturae 4:105-111.

Thibodeau PO, Minotti PL (1969) The influence of calcium on the development of lettuce tipburn. Journal of the American Society for Horticultural Science, Alexandria 94:372-375.

Whitehead CS, Swardt GH (1982) Extraction and senescing leaves of Protea erifolia. South African Journal of Botany 1(4):127-130.

Vidigal SM, Cecílio Filho AB, Mendoza-Cortez JW, Pereira PRG (2019) Diagnóstico visual na avaliação do estado nutricional das hortaliças. Informe Agropecuário 40(308):41-54.

Zambolin L (1998) Estratégias de manejo integrado de doenças. In: WORKSHOP: A interface solo-raiz (rizosfera) e relações com a disponibilidade de nutrientes, a nutrição e as doenças das plantas. Anais...Piracicaba: Potafos. 40p. 